\title{
pseudoaneurysm residing in the common femoral vein diagnosed by ultrasound:a rare case report
}

\author{
Wen-sheng $\mathrm{Xu}^{1}$, Tian-ren $\mathrm{Xu}^{2}$, Feng $\mathrm{Li}^{2}$, and Weiwei $\mathrm{Liu}^{2}$ \\ ${ }^{1}$ Second Hospital of Hebei Medical University \\ ${ }^{2}$ Affiliation not available
}

October 6, 2020

\begin{abstract}
A 73-year-old man was hospitalized for arrhythmia and underwent intracardiac electrophysiologic examination and cryoablation treatment. Because of the complains of pain in the root of right thigh, he underwent arteriovenous ultrasound examination after interventional therapy. Ultrasound showed a heterogeneous mass on the posterolateral wall of the right common femoral vein , which was mainly hypoechoic with small anechoic zone in the center. The pulsation of the anechoic area, the blood flow signal in it, and the characteristics of "to-and-fro" flow spectral pattern proved that the mass was a pseudoaneurysm, not a previously misdiagnosed venous thrombosis.
\end{abstract}

\section{Hosted file}

ECHOCARDIO-manuscript NEW.pdf available at https://authorea.com/users/364789/articles/485078pseudoaneurysm-residing-in-the-common-femoral-vein-diagnosed-by-ultrasound-a-rare-casereport

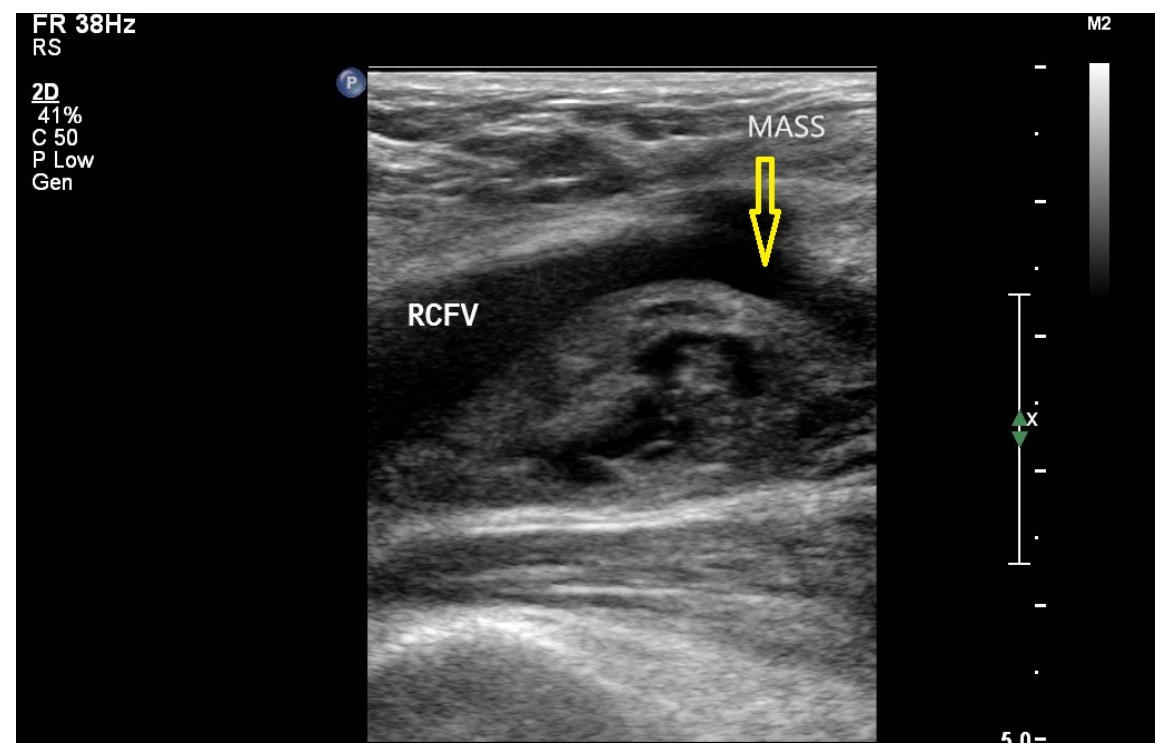



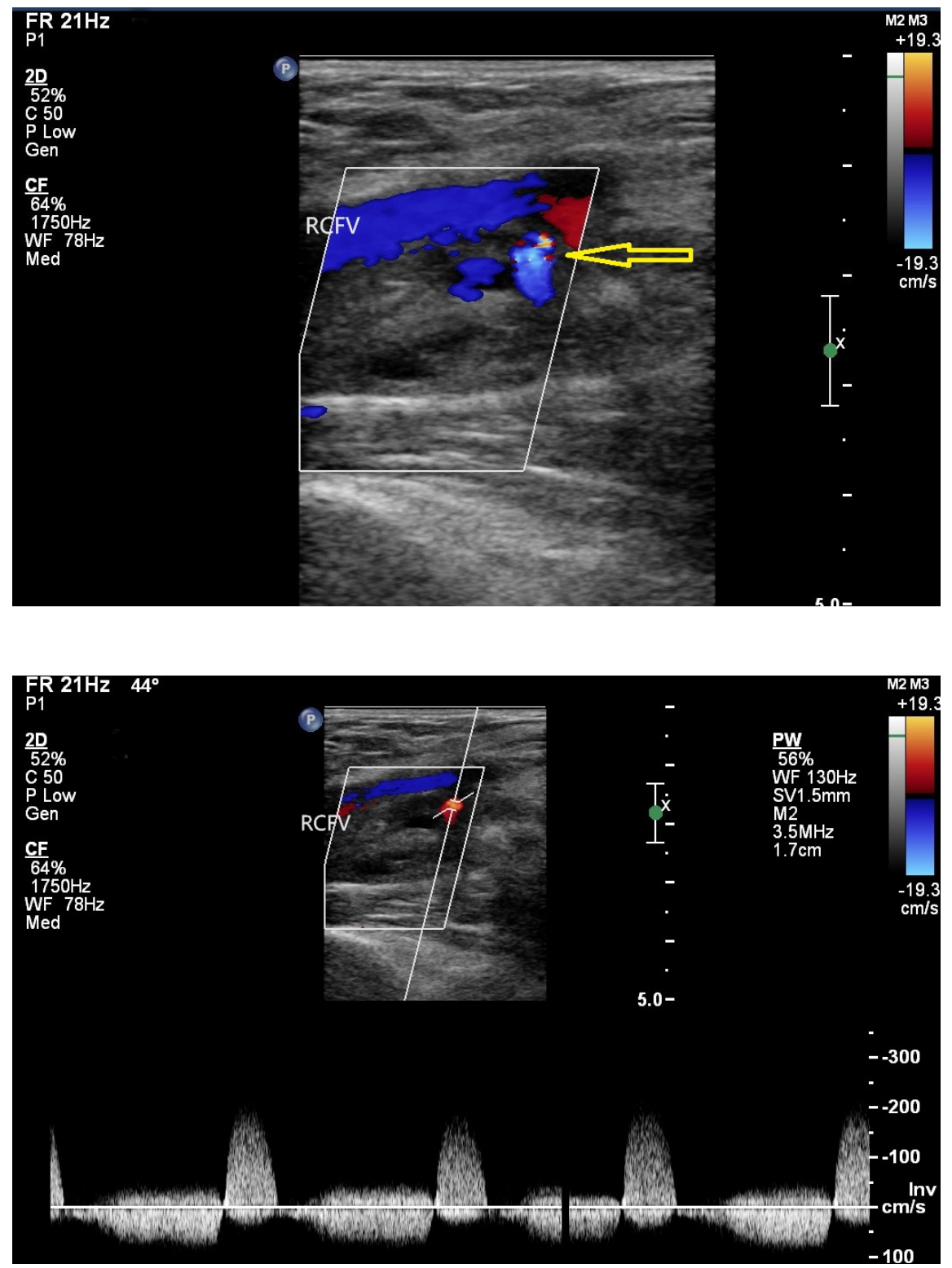

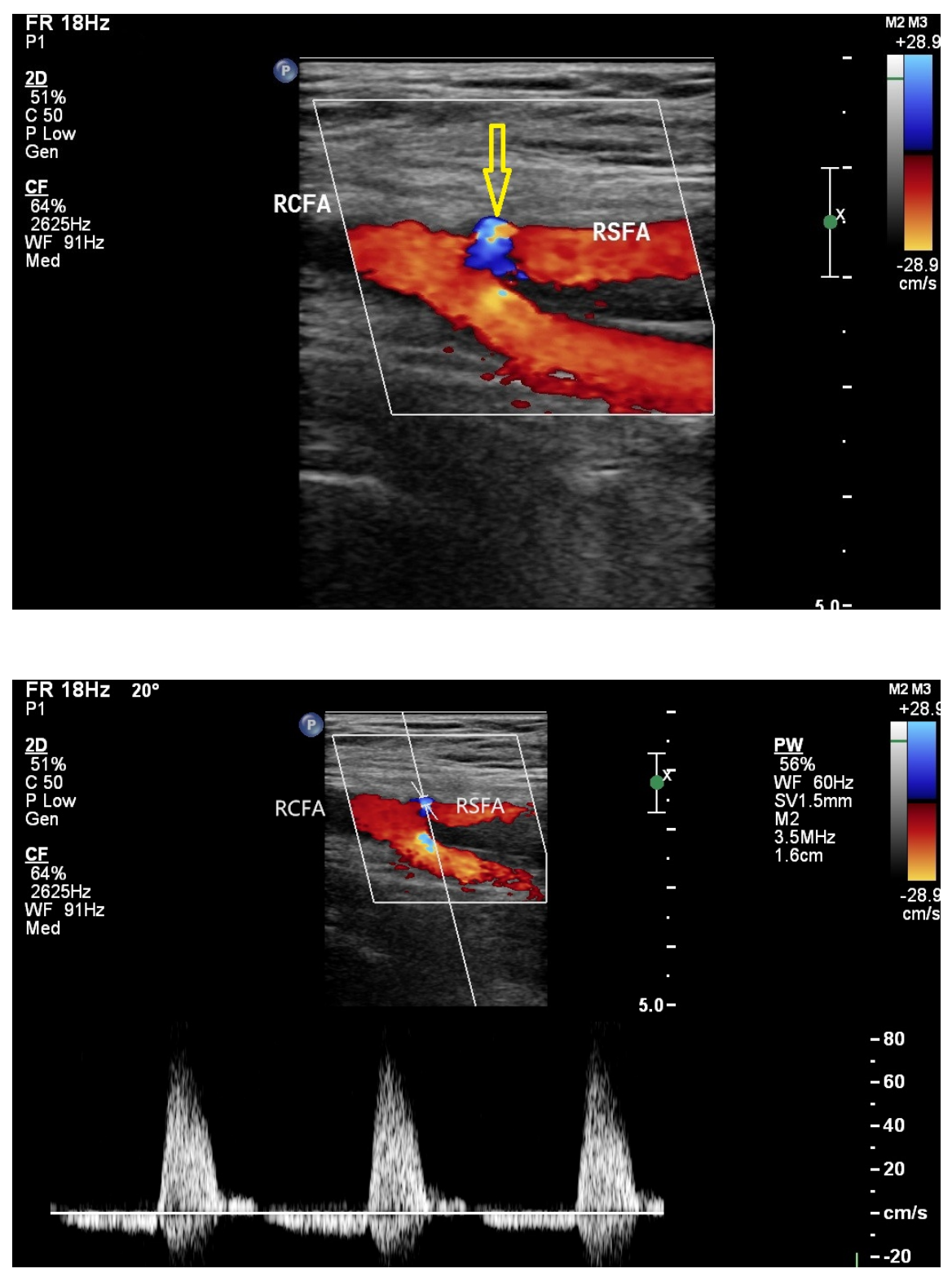